\title{
Hands-on Learning of Commercial Electrical Wiring Practices for Electrical Engineering Students Through Two-University Cooperative Effort
}

\section{Dr. Herbert L. Hess, University of Idaho, Moscow}

Herb Hess received his Ph.D. from the University of Wisconsin in 1993. He then joined the University of Idaho where he is Professor of Electrical and Computer Engineering. His interests are in power electronics, broadly construed, to benefit the people of the Inland Pacific Northwest.

\section{Dr. Brian Peterson, U.S. Air Force Academy}

Brian S. Peterson is a Principal Systems Engineer at the LinQuest Corporation providing technical support to Air Force Space Command in their oversight of strategic and tactical satellite communications. He received his B.S.E.E. degree in 1991 from the United Stated Air Force Academy, an M.S. degree in Systems Engineering in 1995, and his PhD in Electrical Engineering in 2005 from the Air Force Institute of Technology. He also received an M.S.E.E from Florida State University in 1998. Dr. Peterson is a Senior member of IEEE and served as Deputy Department Head in the Department of Electrical and Computer Engineering at the United Stated Air Force Academy until retiring from the military in 2011.

\section{Ms. Susan Elmore, US Air Force Academy}

Susan Elmore received a BA degree from California State University, Sacramento in 1977 and a AS degree in Electronic Technology from Sacramento City College in 1989. She started working for Department of Defense in 1980 in Sacramento and transferred to US Air Force Academy in Colorado in 1994 where she works for the Department of Electrical and Computer Engineering as an Electronic Technician. She is the laboratory technician for the Electrical Power Systems course taught within the department. She is responsible for maintaining the electrical wiring trainer units and power benches that are used in laboratory exercises for this course.

\section{Mr. Al Mundy, United States Air Force Academy}

Al Mundy earned his BSCpE at Clemson University and his MSCpE at Syracuse U. He's currently in a doctoral program at the University of Colorado at Colorado Springs. His interests are in power electronics as well as green/renewable energy. 


\title{
Hands-on Learning of Commercial Electrical Wiring Practices for Electrical Engineering Students Through Two-University Cooperative Effort
}

\begin{abstract}
Development of hands-on training hardware to teach commercial electrical wiring practices at one university extended to another. Motivation is students who graduate to electrical engineering positions without any experience with the electrical codes or in wiring elementary circuits to code requirements. Four different trainer units were created to give students the hands-on opportunity to wire several common circuits. These units have standard 2x4 stud construction. Wires are already run and boxes are already installed for the experiments at hand. In an integrated approach, students learn to make connections and test their circuits against code. Innovative methods of testing and display of the units are shown. Safety procedures are discussed. Each university benefits from the lessons learned by the other. Assessments, both formative and summative, are presented and are used for continuous improvement.
\end{abstract}

Introduction

Many Electrical Engineering students go through their entire program of study without encountering the basic practices required by the National Electrical Code ${ }^{1,2}$. When such topics are taught, they lend themselves strongly to learning by doing; it is difficult to understand without a dominant hands-on component in the instruction. Hardware for training is available through vendors of education products, but the products and the training can be quite expensive. There exists a need for a practical, economical alternative. This paper will describe such an alternative developed through cooperation between two universities, the United States Air Force Academy and the University of Idaho.

The alternative consists of two types of trainer units: student units, intended for hands-on wiring practice and discovery, and a comprehensive "instructor" unit consisting of all of the elements of the student units, designed for demonstration and reference. There are four distinct student units to address the following common household and commercial wiring tasks: Three way switches, ground fault circuit interrupter with downstream load, breaker panel with security light and standard outlet, switched and unswitched outlets.

For teaching a typical section of students at each of the two participating universities, two complete sets of student units and one instructor unit were built. The instructor taught the fundamentals of household and commercial wiring in two or three lessons using the instructor unit as a fully operating demonstrator. Then the students worked in a classroom/lab environment to wire up each of the four student units in turn over two lessons. Section size was 24 students or fewer. Student involvement was enthusiastic; their feedback will be included in the paper's assessment section.

This paper includes descriptions and diagrams sufficient to replicate each unit. This paper contains some discussion of the instruction, sufficient to understand what was covered. Because students train with 120 Volts AC on these units, safety merits extra care. A design for safety is 
explained in detail. After four semesters of use, an assessment of student learning indicates improved proficiency with the concepts and methods and enthusiasm for learning.

\section{Equipment Development}

A search of relevant literature quickly reinforces the notion that equipment for this training is usually developed in-house. This is true of universities, community colleges, technical institutes, and even on-line training. Much of the equipment is large, highly realistic, and definitely not portable.

Universities and community colleges have developed equipment to teach electrical code in a realistic fashion. At the Milwaukee School of Engineering, there is a laboratory with a nice range of electrical panels for teaching distribution wiring. The laboratory focuses primarily on the motor loads. Students get a strong experience in investigating existing installations and in building their own. Their loads are mostly motors and lighting. ${ }^{3}$ California Polytechnic State University has created equipment to teach introductory installation of plumbing, electrical (high and low voltage), and residential security and fire protection. The electrical subset addreses some of the equipment presented in this paper, including simple wiring of receptacles and ground fault circuit interrupters in a semiportable configuration. They include elementary plumbing and low voltage pushbutton loads in a setup remarkable for framed wood studs. ${ }^{4}$ There is an innovative approach at Erie Community College that integrates wiring practices into strong and innovative photovoltaic laboratory equipment analysis and construction. They get an astonishingly great experience for their students for the money. ${ }^{5}$ The best all-around electrical distribution engineering experience and equipment in an engineering college is at the University of Nebraska-Lincoln. They have a complete hands-on experience as well as analysis of existing installation in a beautiful laboratory setting. ${ }^{6}$

As one might expect, there are a host of on-line programs in code training. Some have developed supurb courses and equipment that can be studied remotely. ${ }^{7}$ Others have integrated effective on-site and distance education. ${ }^{8}$ Of course, there are as many local training programs as there are localities. Many are superb in workforce training. They concentrate their equipment focus on building actual installations, first in shop and then on the jobsite. ${ }^{8}$ The programs mentioned here are by no means exhaustive, but merely representative.

Description

The complete circuit set consists of four student units and one instructor unit. The four student units have one each of the following fully functional circuits:

- Three-way light switch set

- Ground Fault Circuit Interrupter (GFCI) circuit

- Household mains circuit breaker panel, security light, and single standard outlet

- Switched outlet circuit

Wiring diagrams for each circuit are shown in Figures 1-4. The instructor unit has all four of these circuits already assembled on a single panel. Complemented by a document camera, the 
instructor unit provides examples for classroom instruction. The instructor unit provides appropriate patterns and solutions for students to check their hands-on laboratory work.

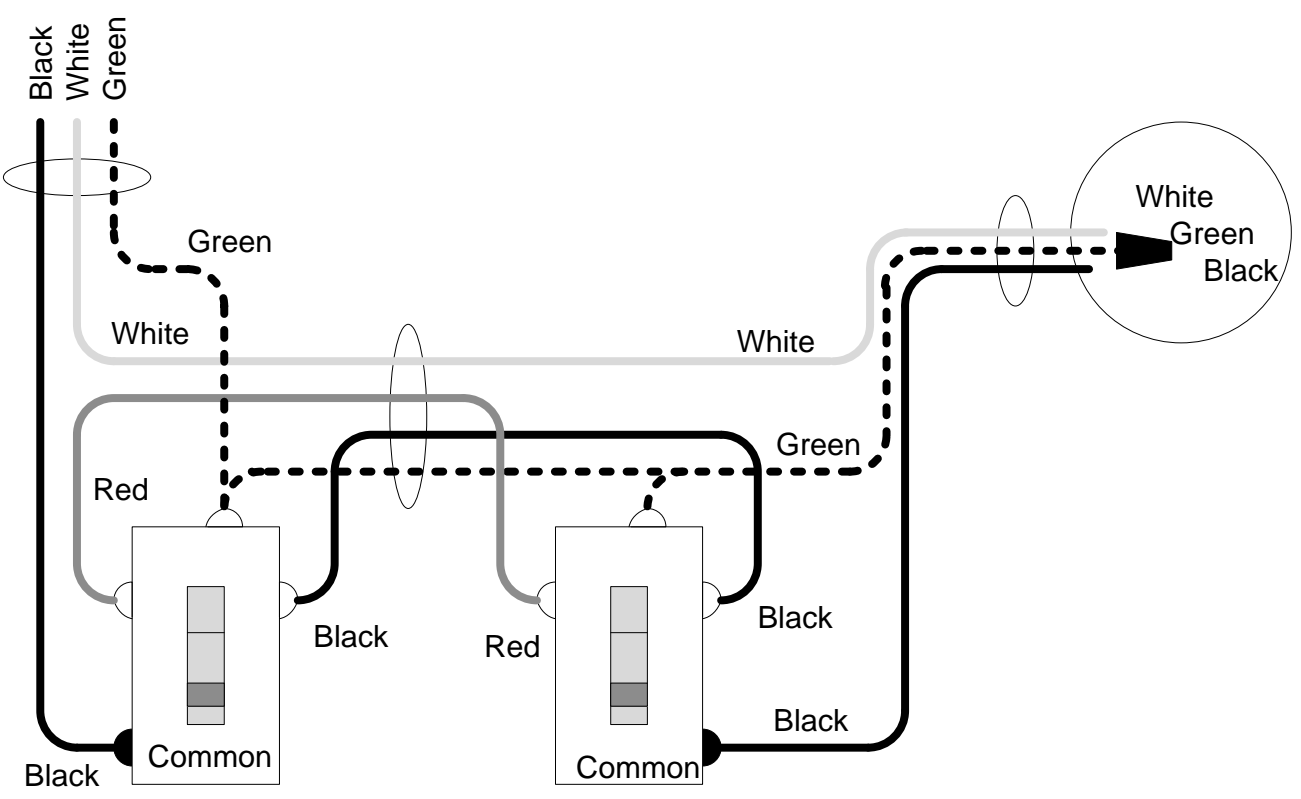

Figure 1. Three Way Switch Circuit Wiring Diagram.

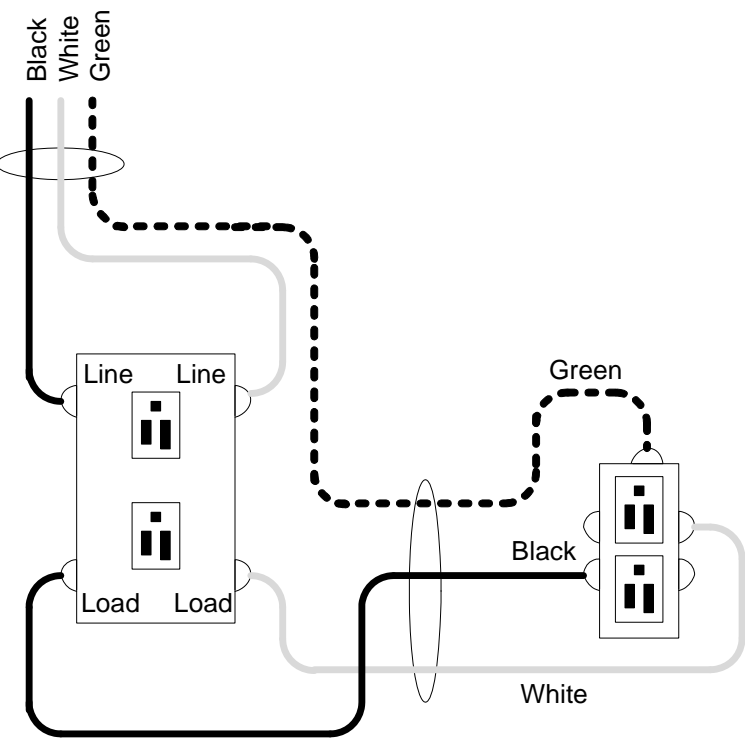

Figure 2. GFCI Circuit Wiring Diagram. 


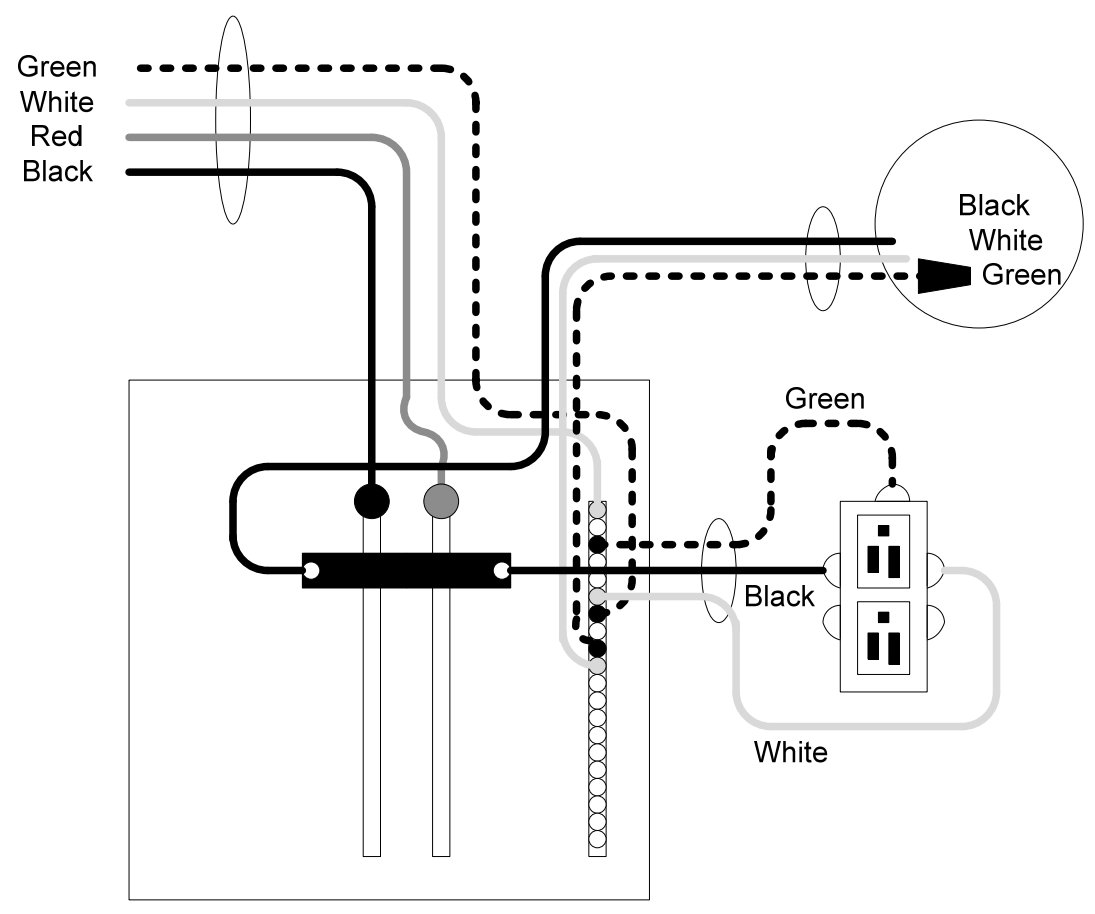

Figure 3. Wiring Diagram for Panel with Receptacle and Security Light.

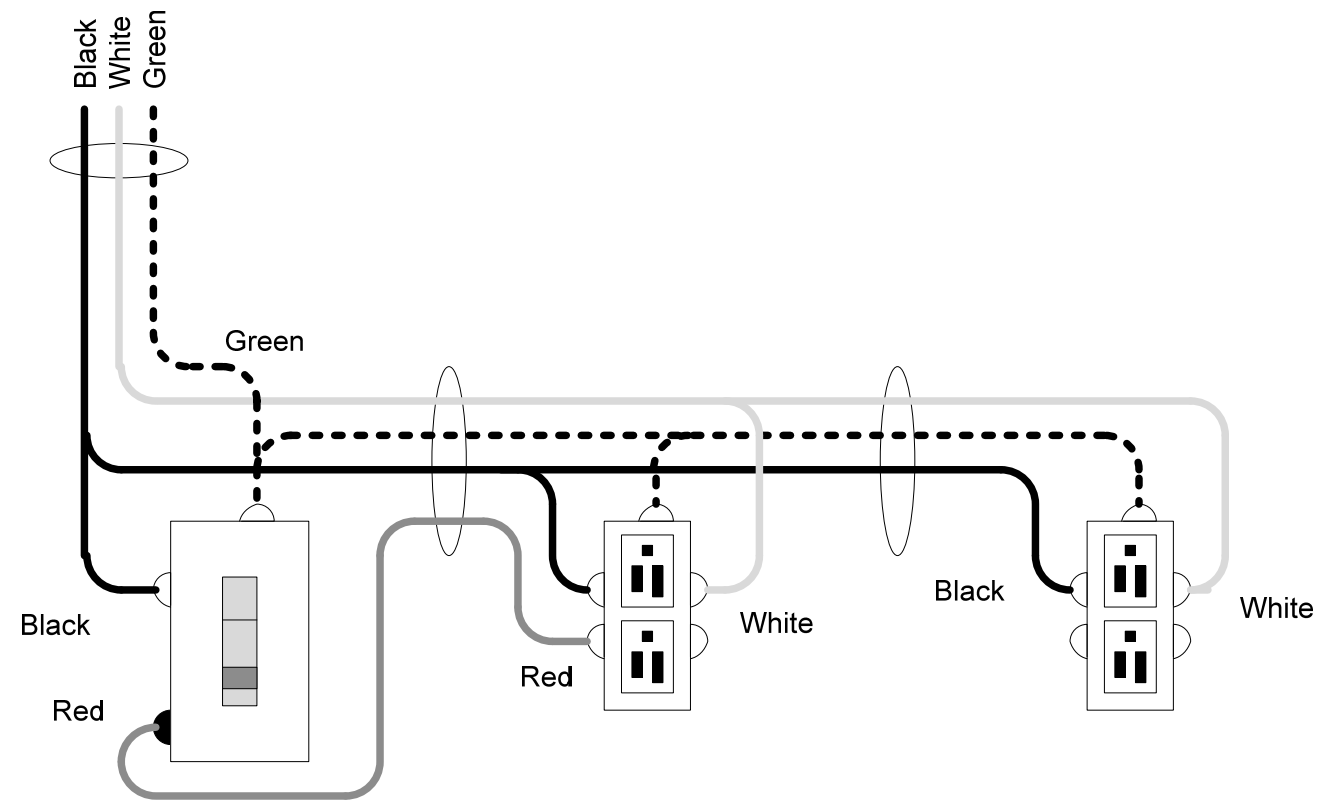

Figure 4. Switched Outlet Circuit Wiring Diagram 
All units are built with standard 2x4 wood studding to resemble a real installation. They are backed with a quarter sheet of plywood (24 x 48 inches) for physical stability. Electrical boxes are properly attached and, for most of them, ROMEX is attached to the $2 \times 4$ structure within each unit. The students need not pull any wire and the ends of each run are already stripped for the experiments at hand. Instructors provide tools, such as screwdrivers, wire cutters, pliers, and a receptacle wiring tester.

Each circuit is powered via a standard computer power supply receptacle, a generic computer power plug, and a standard $120 \mathrm{~V}$ wall outlet. This configuration strongly enhances safety. Design for safety to enable the instructor to control the progress of each experiment is included. How this works is described in the Safety section later in this paper.

An innovative display and storage system was created for these units. Each unit has a strip of $1 \times 6$ attached on the back of the plywood. This $1 \times 6$ is cut with an acute interior angle, allowing it to be hung on a similarly cut piece of $1 \times 6$ attached to a wall as shown in Figure 5. When displayed on the classroom wall, this enables students to see, investigate, and review the units throughout the semester.

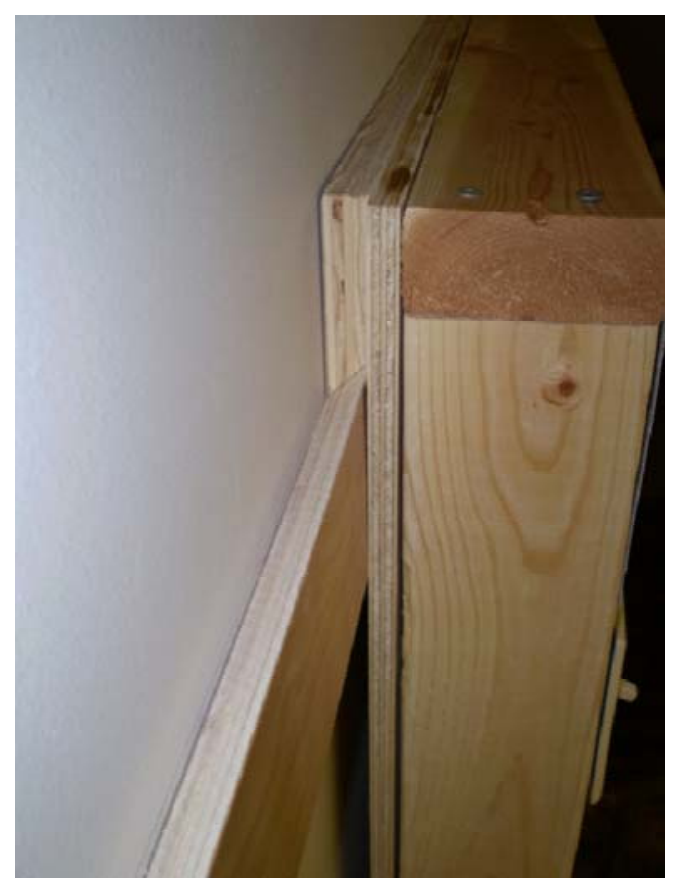

Figure 5. Innovative Mounting Design.

Cost of a complete set of four student units is about $\$ 150$ for materials. From picking up the rough components at a lumberyard to finished, assembled product took the author about six hours for a set of four student units. Photos of the student units are shown in Figure 6. The instructor unit is shown in Figure 7.

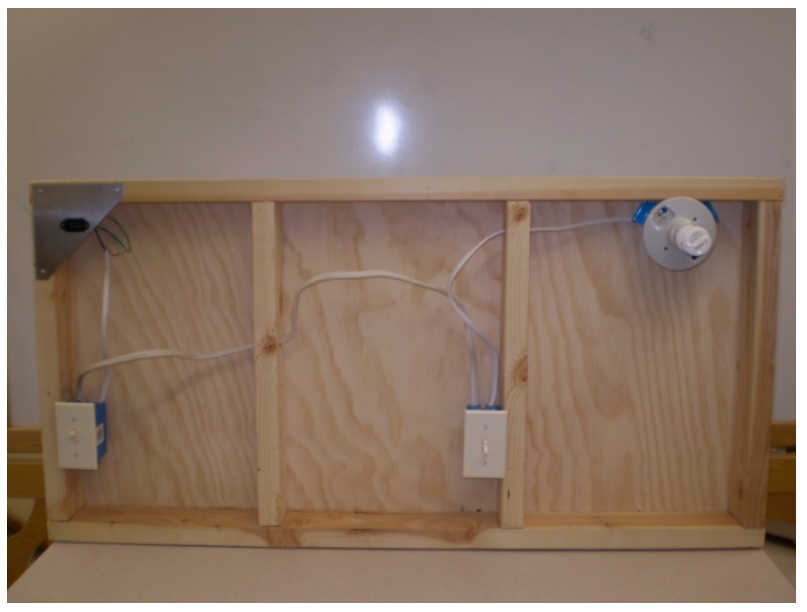

a. Three Way Switch Circuit

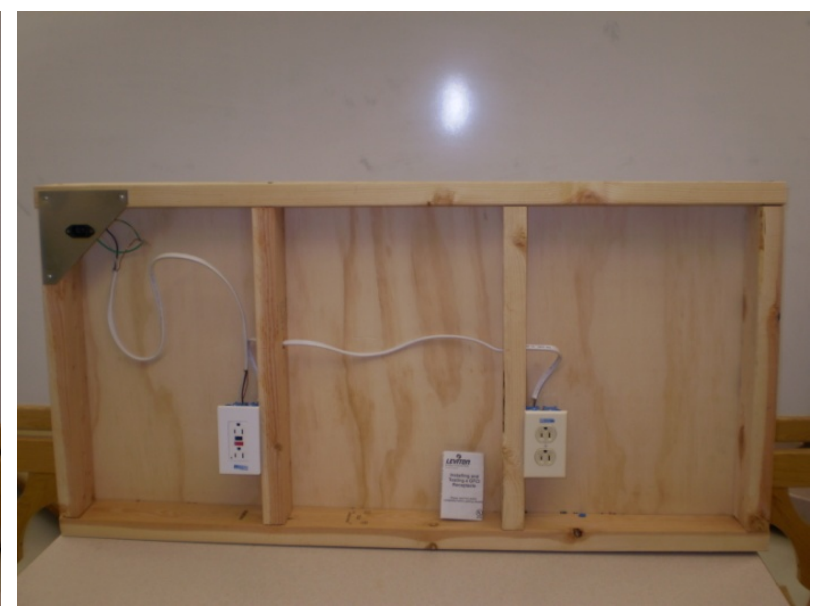

b. GFCI Circuit

b. Figure 6. Photographs of the Four Student Units. 

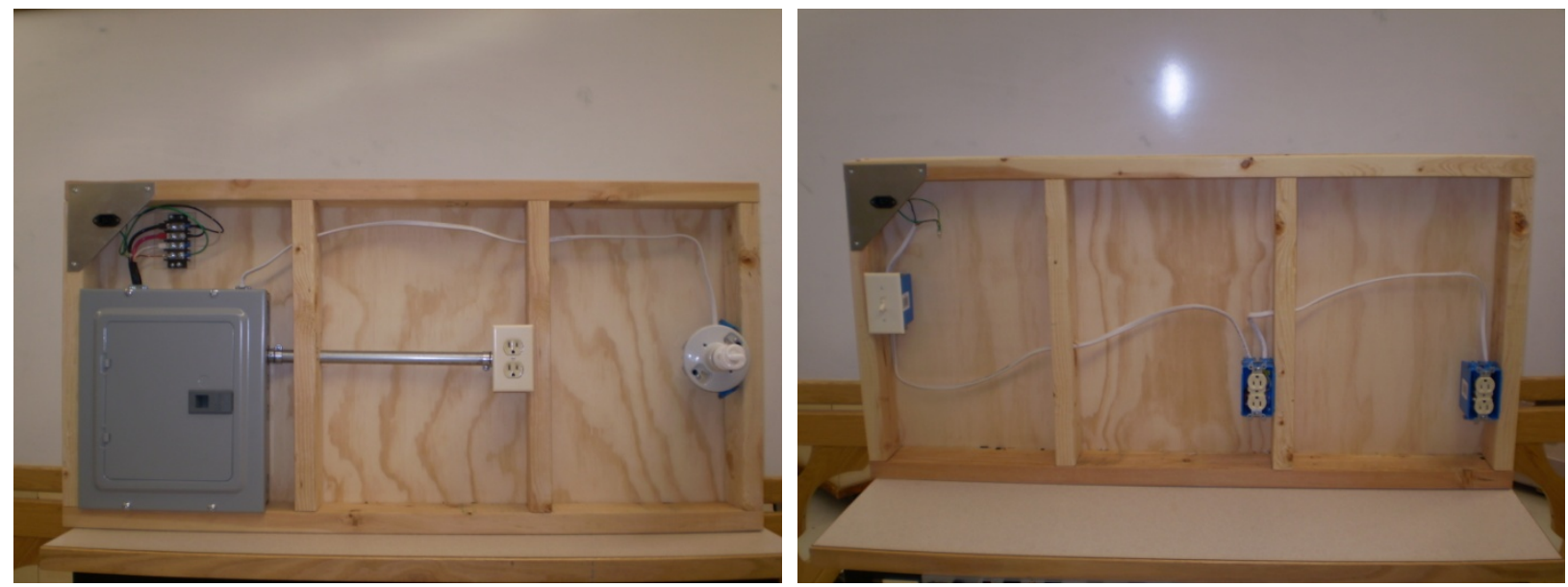

c. Panel with Receptacle and Security Light

d. Switched Outlet Circuit

Figure 6. Photographs of the Four Student Units.

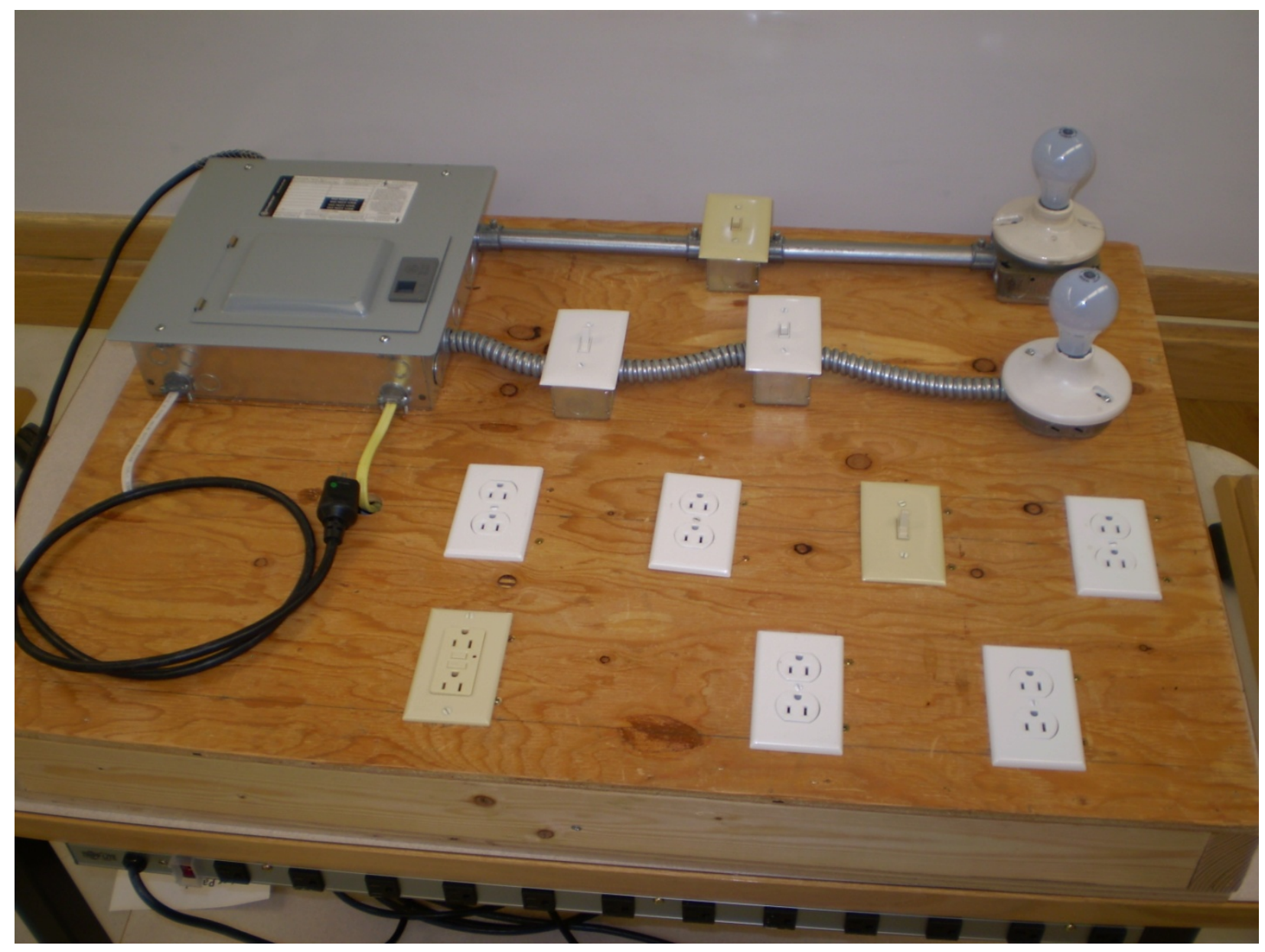

Figure 7. Instructor Unit.

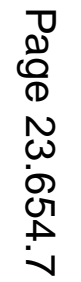




\section{Lab Day}

In the classroom instruction leading up to this laboratory, students learn how to wire each of the four circuits, as well as a few other similar household and commercial circuits. Their prelaboratory homework involves drawing diagrams of some, but not all, of the circuits on the units. All circuits are presented in such a way as to illustrate correct wiring practices such as proper grounding techniques, the use of metal stud plates to prevent nail penetration of wires, and the optional use of a colored marker to identify a hot-wire in a three-way switch. Color code is emphasized.

The lab was run first in the fall semester of 2010 at the Air Force Academy The typical power class there has 15-24 students. For the available four student units, smaller groups of 4-6 students each are formed. After a final safety briefing from a lab technician, students then rotate through as many of the four units as they can in the allotted time. A technician and one or two instructors are sufficient to monitor progress, provide instruction, and maintain safety.

The 3-way and Breaker-box circuits usually take much longer than the light switch and GFCI circuits do. In a single hour-long lesson, no single group wired up all circuits. This was not optimum. The initial solution, applied in the next semester, was to include a second hourlong lesson for the lab work. This gave sufficient time for everyone to work on every circuit. Consequently, when the units were built for the University of Idaho in the fall semester of 2011, two complete sets of the circuitry were created. There, section size is typically 16 students, so two-student teams used two hour-long lessons to complete all the circuitry. An instructor and a teaching assistant were sufficient staffing.

After the laboratory hours, a brief followup homework was required. Homework questions related to circuit construction, color code, and safety. Students had to produce appropriate diagrams showing how to wire two of the four circuits. Student performance on that homework was quite good, with only one or at most two students, getting anything incorrect.

\section{Observations}

After offering this laboratory four times at the Air Force Academy and three times at the University of Idaho, some observations appear common to both universities' students and their work. These serve as important teaching opportunities during review lessons before and after exams.

Issues common to all four circuits. As most students have never seen an outlet or switch as it's being wired, there is significant initial confusion as to how the connectors work. Screw terminals, push in terminals, ground connections, and busbars are unfamiliar and take a bit of extra time the first time they are encountered. Fortunately, most students learn quickly; after all, the point of having hands-on work is to encounter and overcome these issues. Often there were one or two students per section who had experience with the hardware, so this group effort produced a strong learning experience. 
Tools are important. Each group has screwdrivers, wire cutters, and wire strippers. Some students do not know how to use them; Being sensitive to this and providing a little private instruction or help from peers overcomes the problem. Extra wire nuts are necessary, as some invariably get lost or damaged during each session.

Few students draw out the circuit before wiring it. This is not merely an oversight. There is active resistance to doing so even when they get stuck and the instructor asks them to write down a diagram. For the switched and GFCI circuits, this is not a big problem because the circuits are simple. However, students who do not draw a diagram before attempting the threeway switch circuit rarely succeed in correctly wiring the circuitry.

Incorrectly wired circuits may have unused and/or bare wires pointing every which way. This helps identify trouble before applying power. Wire connections may not be tightened down and the slightest touch will cause a short or a disconnect. Hot, Neutral, and GND might be incorrectly wired or even directly shorted. Students who do not understand ground well enough identify themselves in this manner. A simple three-light circuit tester, sold at any hardware store, makes identifying correct wiring possible and often easy.

Three-Way Switch. Even with the installation instructions provided with the 3-way switches, very few groups are able to correctly wire the 3-way without instructor/technician help. The issue is more than merely failing to understand the concept of common and switched terminals. This circuit is too complicated to wire without a diagram. When students actually draw out the schematic and trace it wire by wire, sometimes with instructor help, they usually finish the circuit. The ground wire usually gets left out. An error in identifying the common terminal usually appears in one of the switches operating properly and the other overriding its fellow.

GFCI. Students finish this circuit quickly because it is a rather simple circuit. Operational testing is another matter. The GFCI can engages by simply shorting the outlet HOT to GND . The first tester was a small piece of aluminum foil: As soon as the foil conducts, the GFCI pops open. In fact, there often is a noticeable arc flash. Students found this entertaining, but it is not a safe practice to be teaching. Therefore, a homemade tester that proved to work safely and well was designed as follows: At a hardware or home improvement store, purchase an ordinary electrical plug intended for use as a repair part. A clear plastic plug works best for illustration, but any standard repair plug works fine. Connect a $12 \mathrm{kOhm}$, two-Watt resistor between the HOT and GND terminals. This draws 1.2 Watts at 10mA, the current that the Code specifies to trip the GFCI.

Breaker Box/Panel. The technicians and instructors spent more time with students wiring this circuit than with any of the others. There are a number of new concepts that students do not yet understand well. Like the three way switch circuit, this circuit is complicated and difficult to build without a diagram.

Students have seen breakers but do not really understand how they operate or how they are connected. They find it difficult to understand which wires, if any, are HOT and which are not. Their struggle presents an excellent teaching opportunity about breaking the HOT wire and 
maintaining continuous NEUTRAL and GND wires. They do not initially see how the NEUTRAL wire is connected or the notion of single point grounding on the bus bar.

The student units use single phase 120 Volt AC, but the panel requires 240 Volts AC center tapped for the neutral. Those two HOT wires are difficult to create accurately and safely from the 120 Volts single phase AC input, not to mention the greater danger of 240 Volts AC. A solution that works for the situation at hand is to run heavy AWG 2 RED and BLACK wires both from the point where power enters the unit to the two poles of the panel. At least, this creates an illusion of two HOT wires and energizes two distinct breakers to make the point. When presented this way, with appropriate thick wires and color code, the students seemed to understand not only the operation of the two poles, but also the nature of the illusion being created.

Instructor unit. The instructor unit is merely the union of all of the student units, compiled on a single board. During the laboratory sessions, the instructor unit is left open but correctly wired to serve as a model. Few students used it as such a reference.

While primarily intended for use in the Electric Power Course, the circuits are available as demonstrations for any other instructor that would like to use them in other classes. Simple to use and already constructed, they are ideal for this type of no-notice instructor use. The renewable energy course repeated the lab and realized a noticeable improvement in the time that it took to wire up each circuit as well as the accuracy. There was still a resistance to writing a diagram, which had predictable results.

These are some of the issues and fine points that the student encountered. Overall, the units appear successful in teaching basic wiring, as the Assessment section of this paper explains. Safety

For nearly all of the students, this is the first encounter with dangerous voltages in a laboratory environment. Few have seen electrical sockets or fixtures unless fully assembled. Most have no hands-on experience at all with residential or commercial wiring practices. Any electrical experience that most of them possess is from the prerequisite basic circuits laboratory and / or physics laboratories. All of that is low voltage, usually less than 15 Volts DC or less, and current limited by the laboratory apparatus. Electric shock has not really been an issue or even a conscious consideration so far. That changes with the live 120 Volts AC that these laboratory exercises require.

A lesson on simple safety precautions has proven sufficient. Students all know enough not to poke their fingers or paper clips into electrical receptacles or light sockets. From there, the lesson proceeds to address the following:

- Biomedical effects of electrical shock

- The role of current in electrical shock hazards

- The One-Hand Rule

- The Two-Person Rule 
- The Rule that requires that a circuit be completely built before connecting to electrical power and requiring disconnection from electrical power before making modifications

- How the National Electrical Code (NEC) protects equipment from fire

- How Ground Fault Circuit Interrupters protect people.

At the Air Force Academy, laboratory preparation begins with a full lesson on high voltage safety. A prelaboratory exercise, required as homework, emphasizes both wiring and safety. The exercise consists of a sequence of questions ,such as the following:

- What color is the HOT in a residential electrical system?

- Draw the schematic of a three-way light switch system.

- How do we obtain 240VAC from 120VAC?

Likewise, at the University of Idaho, nearly a full lesson is presented on safety, ending in a quiz, on the second lesson of the semester. Safety is reviewed before beginning any laboratory "hands-on" work with high-voltage.

While in the laboratory, students built their circuitry without electrical power available. When they believed that their work was ready for testing, they asked the instructor for permission to apply power. Power was applied only with an instructor, teaching assistant, or technician present. The student laboratory experiment units all had a male computer power supply receptacle as shown in Figure 8. The students' experiments at hand used no computer power supply or "plug-in” instrumentation. Those instruments and, more importantly, their power cords, were all safely locked away. The instructor carried the only cord that fit the receptacle to apply power to the students' units. Students completed the wiring, but electrical power was applied by the instructor after an inspection of their work. With this method, after four semesters, no student has yet been shocked while working on this lab. 


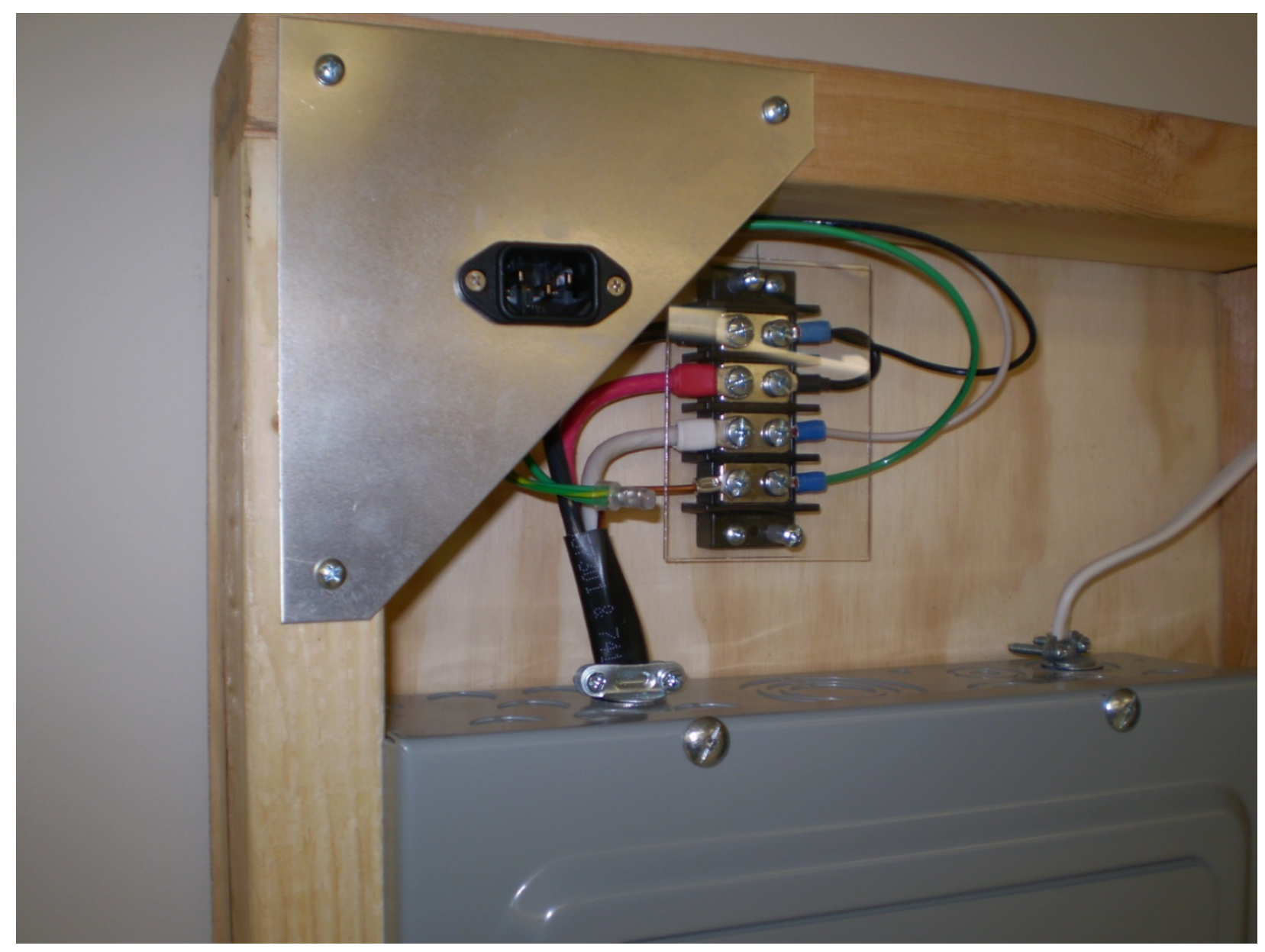

Figure 8. Electrical Power Entrance on Student Units

\section{Assessment}

These units are a new design, but tested with students for four semesters. Therefore, some assessment may be made of the usefulness of the lab, student understanding of the material, and the success or failure of the lab itself. This assessment is based on student performance, student feedback, and instructor interpretation of student impressions.

Assessing the success/failure and student understanding of any lab can be difficult and this one is no different. Due to the hands on nature of the lab, there is no formal post-lab report. There was, however, a "generalized" short answer question and a wiring diagram question on the next available exam and on the final exam. These questions test the common aspects of the lab while bearing in mind that not all students may have completed all four circuits due to time constraints. Prior to the inception of this lab at the Air Force Academy, these exam questions had marginal success rates. Since this hands-on format was instituted, the results of these questions have improved significantly. Likewise, at the University of Idaho, success rates on the exam questions rose for less than $50 \%$ to above $90 \%$, both on the short answer question and on the wiring diagram question. 
Some sample questions are:

"Explain the purpose of the three wires in a common household circuit".

"Which is the HOT wire in a household circuit - BARE, BLACK, or WHITE?"

"What should be done with the BARE ground wire in a two-wire light?"

"What is the purpose of the National Electrical Code?"

When a hands-on wiring of a circuit from the laboratory was presented on an exam in the renewable energy course at the Air Force Academy, all of the students wired the circuit perfectly, from color code and polarity all the way down to securing the wires screws tightly in the right direction.

Assessing the usefulness of the lab can't easily be done as it might be years before students actually have a need for the material. However, we do ask for student feedback on the lab and most comments are similar to one of the following:

"This lab gave me an understanding of how switches work."

"I never knew that three-way lights are so complicated."

"I will hire an electrician".

Student enthusiasm also appeared for an unexpected assessment. When finished with the lab, the trainers were left in various states of assembly or lack thereof. For a single technician at the University of Idaho, reassembling all nine units for storage and display was a big job. The instructor instead announced a "wiring party" in class and scheduled it during final exams. Of sixteen students each of three semesters, six or seven attended and helped reassemble the circuitry. In a half hour, everything was done. On the final exam, all of those who attended the "wiring party" answered all of the pertinent questions perfectly.

\section{Conclusions}

Students in Electrical Engineering often lack the opportunity to study even the elementary practical aspects of the National Electrical Code. These are best learned in a hands-on environment. Incumbent commercial hardware for teaching this exists, but it can be quite expensive. In this paper, a relatively inexpensive (\$150 a set) alternative is presented. It consists of four student units, which students wire themselves in the laboratory, and an instructor unit, used for demonstration and examples. Successful teaching with these units included a lesson or two on the proper wiring techniques and circuits and a lesson on safety. In the laboratory, after a final lesson on safety, students learned by doing. Observations and feedback at one university led to improvements or, at least, mitigation of difficulties. To use the units, safety methods were specially developed to maintain control at all times and to enforce safe practices. Innovative hardware and procedures for testing, storage, and display was also invented. Assessments seemed to indicate a significant improvement in understanding, in hands-on skills in wiring circuitry, and in enthusiasm at both universities. 


\section{References}

${ }^{1}$ National Fire Protection Association, National Electrical Code 2011 (Quincy, Massachusetts: National Fire Protection Association, 2010).

${ }^{2}$ National Fire Protection Association, National Electrical Code Handbook 2011 (Quincy, Massachusetts: National Fire Protection Association, 2010).

${ }^{3}$ J. Wheeldon and G. Wrate, "Development of a Cour-Course Sequence in Building Electrical Power Distribution," ASEE Annual Conference 2002, Montreal, Quebec, Canada, June 2002, pp. 4-7.

${ }^{4}$ T. Korman and L. Simonian, "Design and Use of Interacive Learning Stations in Construction Education for Building Mechanical, Electrical, and Plumbing Systems,” ASEE Annual Conference 2008, Pittsburgh, Pennsylvania, June 2008, pp. 7-8.

${ }^{5}$ E. Brewer and A. Dalessio, "Effective Low-Budget Approach to Teaching Photovoltaic Systems to Electrical Engineering Technology Students at Community Colleges,” ASEE Annual Conference 2012, San Antonio, Texas, June 2012, pp. 5-10.

${ }^{6}$ M. Alahmad, H. Hess, and B. Johnson, "Project Based Approach to Introduce Building System Design in an Electrical Engineering Curriculum,” ASEE Annual Conference 2007, Honolulu, Hawaii, June 2007, pp. 5-7.

${ }^{7}$ US Solar Institute, “Electrical Code Training Equipment and Courses,” http://ussolarinstitute.com/electrical-codetraining-why-you-need-it-when-installing-solar/, US Solar Institute, Fort Lauderdale, Florida, 2010.

${ }^{8}$ NTT Inc, “National Electrical Code Training," http://www.nttinc.com/courses/on-site/national-electrical-code , NTT Inc., Denver, Colorado, 2012.

${ }^{9}$ Lake Area Technical Institute, “Workforce Training,” http://www.lakeareatech.edu/corped/workforce.html, Lake Area Technical Institute, Watertown, South Dakota, 2011. 